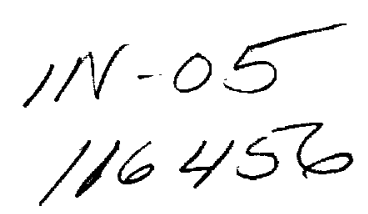

NASA Technical Memorandum 107654

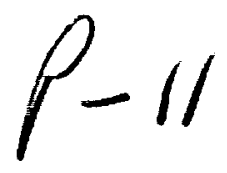

\title{
ROLLING MANEUVER LOAD ALLEVIATION USING ACTIVE CONTROLS
}

Jessica A. Woods-Vedeler and Anthony S. Pototzky

July 1992

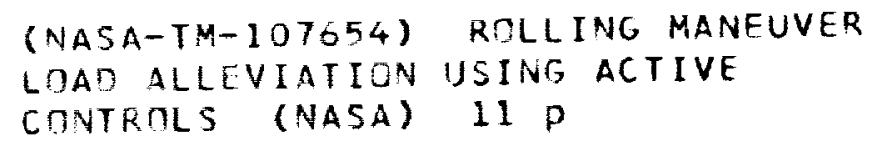

$N 92-31351$

Unclas

$63 / 05$

0115456

\section{N/SN \\ National Aeronautics and Space Administration}

Langley Research Center

Hampton, Virginia 23665-5225 


\title{
ROLLING MANEUVER LOAD ALLEVIATION USING ACTIVE CONTROLS
}

\author{
Jessica A. Woods-Vedeler* \\ NASA Langley Research Center \\ Hampton, VA 23665 \\ Anthony S. Pototzky** \\ Lockheed Engineering and Science Company \\ Hampton, VA 23666
}

\begin{abstract}
Rolling Maneuver Load Alleviation (RMLA) has been demonstrated on the Active Flexible Wing (AFW) wind-tunnel model in the NASA Langley Transonic Dynamics Tunnel. The design objective was to develop a systematic approach for developing active control laws to alleviate wing incremental loads during roll maneuvers. Using linear load models for the AFW wind-tunnel model which were based on experimental measurements, two RMLA control laws were developed based on a single-degree-of-freedom roll model. The RMLA control laws utilized actuation of outboard control surface pairs to counteract incremental loads generated during rolling maneuvers and actuation of the trailing edge inboard control surface pairs to maintain roll performance. To evaluate the RMLA control laws, roll maneuvers were performed in the wind tunnel at dynamic pressures of 150,200, and $250 \mathrm{psf}$ and Mach numbers of $0.33, .38$ and .44 , respectively. Loads obtained during these maneuvers were compared to baseline maneuver loads. For both RMLA controllers, the incremental torsion moments were reduced by up to $60 \%$ at all dynamic pressures and performance times. Results for bending moment load reductions during roll maneuvers varied. In addition, in a multiple function test, RMLA and Flutter Suppression System (FSS) control laws were operated simultaneously during roll maneuvers at dynamic pressures $11 \%$ above the open-loop flutter dynamic pressure.
\end{abstract}

\section{Nomenclature}

\section{$[\mathrm{A}],[\mathrm{B}],[\mathrm{C}],[\mathrm{D}],\{\mathrm{E}\}$ coefficient matrices}

$\mathrm{G}$ controller transfer function

$\mathrm{G}_{1}, \mathrm{G}_{2}, \mathrm{G}_{3} \quad$ control system gains

g

$\stackrel{\mathrm{H}}{\mathrm{H}}$

$\mathrm{I}_{\mathbf{x x}}$

$\mathrm{K}_{\mathrm{c}}, \mathrm{K}_{1}, \mathrm{~K}_{2}, \mathrm{~K}_{3}$

LEO

$\mathrm{L}_{\mathrm{p}}$

$\mathrm{L}_{\delta}$

I

$\mathrm{M}$

m

q TEI

TEO

$\mathrm{t}_{\mathrm{f}}$ tff

$\mathbf{x}, \dot{\mathbf{x}}$

$\mathrm{y}$

$\delta$

$\phi, \dot{\phi}, \ddot{\phi}$

$\omega$

Subscripts
b
c
I
i
L
O
p
pm
R
t

time to free-fall through $90^{\circ}, \mathrm{sec}$ input variable

state variable and its time derivative output variable

control surface deflections, degrees

roll angle and its time derivatives

frequency, $\mathrm{rad} / \mathrm{sec}$

bending

control surface

inboard location

control surface index

left wing

outboard location

roll rate

pendulum

right wing

torsion

Introduction

In the past 20 years, active controls has been investigated extensively as a means to control the aeroelastic response of an aircraft. Gust load alleviation using active controls has been successfully implemented on aircraft such as the Lockheed L1011 ${ }^{1}$ and the AIRBUS A320 ${ }^{2}$. Flutter suppression has been demonstrated through wind-tunnel testing of a variety of aircraft ${ }^{3,4}$ and validated in flight testing on such aircraft as the $B-52^{5}$ and the $F-4 F^{6}$. Before the use of active controls for these purposes, it was necessary to provide a passive solution to the suppression of unfavorable aeroelastic response which involved increasing the structural stiffness and, thus, the weight of a wing structure.

An active controls capability, however, has not been developed for alleviating wing loads generated during roll maneuvers. Consequently, aircraft wings are designed to support the increased loads generated during roll maneuvers through added structural stiffness. The resultant increase in wing weight of the designed aircraft may be unnecessary if active controls technology is available to alleviate loads. Some past research has indicated the feasibility of rolling maneuver load alleviation using active controls.

During early testing of the Active Flexible Wing (AFW) wind-tunnel model in $1987^{7}$, an Active Roll Control system (ARC) was developed to maneuver the model to a commanded roll angle position at a specified roll rate. During evaluation of the control law, the potential for using active controls to redistribute wing loads during roll maneuvers was recognized. A systematic approach for designing control laws to reduce wing loads during roll maneuvers, however, was not developed.

* Research Engineer, Member AIAA
** Staff Engineer, Member AIAA 
During the same 1987 test, two maneuver load control systems were demonstrated for longitudinal motion of AFW. The concepts involved reducing a wing root bending moment during pitch maneuvers through the use of angle-of-attack feedback, scheduled wing cambering using control surface deflections and, for one of the controllers, bending moment strain gage feedback. Significant reductions in bending moment were achieved. Based on this success, the possibility of designing a control law to actively reduce wing loads during roll maneuvers was considered very good.

Thus, the intent of the current research is to develop the capability to alleviate wing loads during roll maneuvers of an aircraft using active controls. The approach involved evaluating the ability of each control surface to affect loads during a roll maneuver. More specifically, in this paper, a systematic approach is defined to develop RMLA control laws. Using this approach, two RMLA control laws, which differ by which control surface pairs are active during roll maneuvers, are developed. During the development of these control laws, the effect of an off-axis model mass center on RMLA performance is briefly discussed. The two RMLA control laws were experimentally evaluated by performing controlled roll maneuvers of the AFW model in the Langley Transonic Dynamics Tunnel at dynamic pressures of $150,200,250 \mathrm{psf}$ at Mach numbers of $0.33, .38$ and .44 , respectively. Load alleviation results obtained during the controlled roll maneuvers are presented in this paper. In addition, results from roll maneuvers controlled simultaneously by an RMLA control law and a flutter suppression control law and performed at dynamic pressures above the open-loop flutter dynamic pressure are presented.

\section{Active Elexible Wing Wind-Tunnel Model}

The Active Flexible Wing (AFW) wind-tunnel model ${ }^{7}$ used in this research was developed by Rockwell International Corporation. It was an aeroelastically scaled full-span model of an advanced fighter configuration. The model had an $8.7 \mathrm{ft}$ wing span and was free to roll about the sting mount. A hydraulic braking system was used to stop the model during rolling maneuvers when necessary. Because the model was used as a test bed to evaluate other advanced aeroservoelastic technology such as flutter suppression, it had two mass ballasts attached to the wing-tips which could be automatically decoupled from the wing structure to rapidly increase the flutter speed of the model during testing and, therefore, prevent damage to the model.

Each wing of the AFW wind-tunnel model had two leading edge and two trailing edge control surfaces as shown in Figure 1. One leading edge and two trailing edge control surface are shaded on each wing to indicate which control surfaces were used in the current study. Each control surface had a chord which was 25 percent of the local wing chord and a span which was 28 percent of the wing semispan.

The wind-tunnel model was instrumented with several types of sensors. In this study, the sensors of interest were the strain-gage bridges which measured bending and torsion moments and the roll-rate gyro which measured roll rate. Figure 1 illustrates the placement of these sensors. Bending and torsion moment strain gages were positioned at inboard and outboard locations on each wing, while the roll-rate gyro was located at an inboard location on the left side of the model.

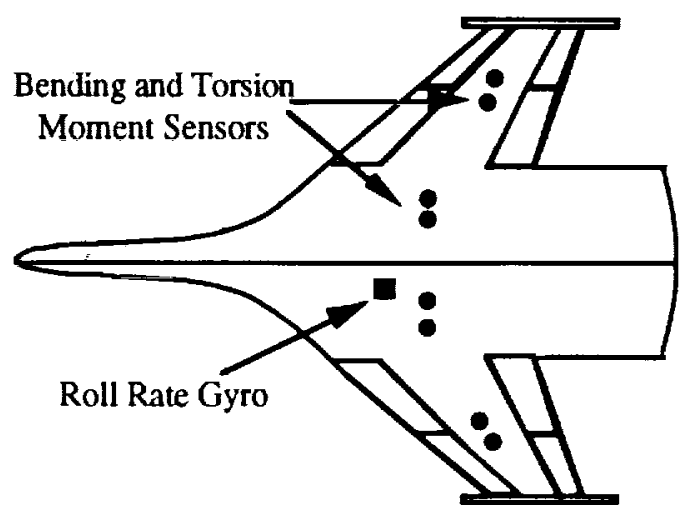

Fig. 1 Sensor and Control Surface Locations

\section{Description of Wind Tunnel}

The NASA Langley Transonic Dynamics Tunnel (TDT) is a closed-circuit, continuous-flow tunnel which has a 16-ft. square test section. Mach number and dynamic pressure may be varied simultaneously or independently. During the current investigation, air was used as the test medium.

\section{Design Obiective}

The objective of this research was to develop active control laws which alleviate bending and torsion moment wing loads during roll maneuvers. Specifically, control laws were designed to minimize the deviation of wing loads from their steady state values in roll maneuvers. This deviation of a load from its steady state value is referred to as an "incremental" load and is illustrated in Figure 2. The dot in the figure indicates the peak value of the incremental load which was attained during a roll maneuver. It is the absolute value of this peak incremental load which the RMLA control laws were designed to reduce.

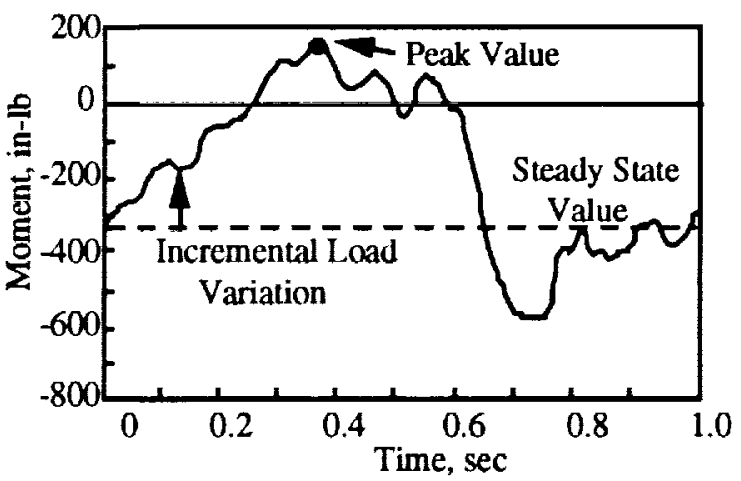

Fig. 2 Wing Load Time History Illustrating Concept of Incremental Load

In addition to reducing incremental loads, the control laws were designed with performance and stability objectives. Each control law was required to roll the model $90^{\circ}$ in 0.75 seconds. The stability requirement was $+4 \mathrm{db}$ gain margin and $+30^{\circ}$ phase margin.

Two types of control laws were developed: RMLA and Baseline control laws. The RMLA control laws were designed to reduce peak incremental loads and to meet the performance 
and stability objectives. The Baseline control law was designed to meet the performance and stability objectives only and served as a basis for evaluating load reduction achieved during implementation of the RMLA control laws.

\section{Plant Model Development}

During the $1987 \mathrm{AFW}$ wind-tunnel test, an active roll control system ${ }^{8}$ designed to minimize control surface deflections during roll maneuvers was experimentally evaluated. The system was designed using only the rigid body roll equation and no flexible modes. Because analytical and experimental results compared well in this previous study, it was considered sufficient to design RMLA control laws in the present study using only the rigid body roll equation.

The design model consisted of an equation of motion and the loads equations. The equation of motion used in this study, which contains no flexible effects, was as follows:

$$
\mathrm{I}_{\mathbf{x} \mathbf{\phi}} \ddot{\phi}=\mathrm{L}_{\mathbf{p}} \dot{\phi}-\mathrm{mgl} \sin \phi+\sum_{\mathrm{i}=1}^{6} \mathrm{~L}_{\delta_{\mathrm{i}}} \delta_{\mathrm{i}}
$$

In this equation, $I_{\mathbf{x x}} \ddot{\phi}$ is the resultant rolling moment acting on the AFW model during roll and $L_{p} \dot{\phi}$ is the aerodynamic moment induced by roll rate. The $\mathrm{mgl} \sin \phi$ term is moment due to an eccentricity of the model mass center below the roll axis and the last term is the aerodynamic rolling moment due to control surface deflection. The $\mathrm{mgl} \sin \phi$ is referred to in this paper as the pendulum contribution and is not representative of real aircraft. Its effect on the design of an RMLA is examined later.

The equations describing AFW model total loads during roll were written as

$$
\{y\}=[C]\{x\}+[D]\{u\}+\{E\}
$$

where,

$$
\{y\}=\left\{M_{t_{L I}} M_{t_{L O}} M_{t_{R I}} M_{t_{R O}} M_{b_{L I}} M_{b_{L O}} M_{b_{R I}} M_{b_{R O}}\right\}^{T}
$$

The elements of $[C],[D]$ and $\{E\}$ were determined experimentally.

A linearized state space representation of (1) may be written as

$$
\{\dot{\mathbf{x}}\}=[\mathrm{A}]\{\mathbf{x}\}+[\mathrm{B}]\{\mathbf{u}\}
$$

where,

$$
\begin{gathered}
\{\mathbf{x}\}=\left\{\begin{array}{ll}
\dot{\phi} \phi
\end{array}\right\} \\
\{\mathbf{u}\}=\left\{\delta_{\mathrm{LEO}_{\mathrm{L}}} \delta_{\mathrm{TEO}_{\mathbf{L}}} \delta_{\mathrm{TEI}_{\mathrm{L}}} \delta_{\mathrm{LEO}_{\mathrm{R}}} \delta_{\mathrm{TEO}_{\mathrm{R}}} \delta_{\mathrm{TEI}_{\mathrm{R}}}\right\}^{\mathrm{T}} \\
{[\mathrm{A}]=\left[\begin{array}{cc}
\frac{\mathrm{L}_{\mathrm{p}}}{\mathrm{I}_{\mathrm{Xx}}} & -\frac{\mathrm{mgl}}{\mathrm{I}_{\mathrm{Xx}}} \\
1 & 0
\end{array}\right] .}
\end{gathered}
$$

and,

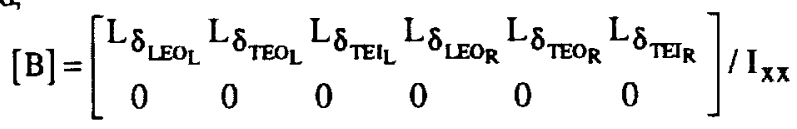

Again, because adequate information describing the rolling moment due to roll rate, $\mathrm{L}_{\mathrm{p}}$, was not available, the $\mathrm{A}_{11}$ term of $[A]$ was determined experimentally. Elements of $[B]$, the control surface effectiveness coefficients, were taken directly from the results of previous AFW testing. A discussion of the techniques used to develop the design model equations used in this study is presented in Reference 9.

\section{Control Law Development}

The approach used in this study to develop RMLA control laws was based on observations of how incremental loads varied during roll maneuvers and how control surface deflections affected these loads. For instance, it was observed that a major component of the incremental loads generated on the AFW model during a roll maneuver were linearly proportional to the roll rate. Thus, direct feedback of the roll rate to control surfaces could reasonably be used to counteract the incremental loads. Furthermore, it was possible to take advantage of each control surface's relative roll effectiveness and each control surface's relative ability to affect incremental loads during roll maneuvers. More specifically, although the trailing edge inboard control surfaces demonstrated much larger roll effectiveness characteristics than the outboard control surfaces, the outboard control surfaces demonstrated a more substantial ability than the trailing edge inboard control surfaces to affect incremental loads during roll maneuvers. This implies that the outboard surfaces could be deflected a limited amount in either the positive or negative sense during a maneuver in order to alleviate loads. Any roll performance lost due to this actuation of outboard control surfaces was regained by a slightly increased deflection of the trailing edge inboard control surfaces.

Thus, the RMLA control laws were developed to utilize the trailing edge inboard control surface pair for maintaining roll performance of the vehicle while outboard control surfaces were used specifically to reduce incremental loads. Incremental loads generated during a rolling maneuver could be reduced without a roll performance penalty.

The RMLA control law structure used in this study is illustrated in Figure 3. As mentioned, the structure includes roll rate feedback to the trailing edge inboard, leading edge

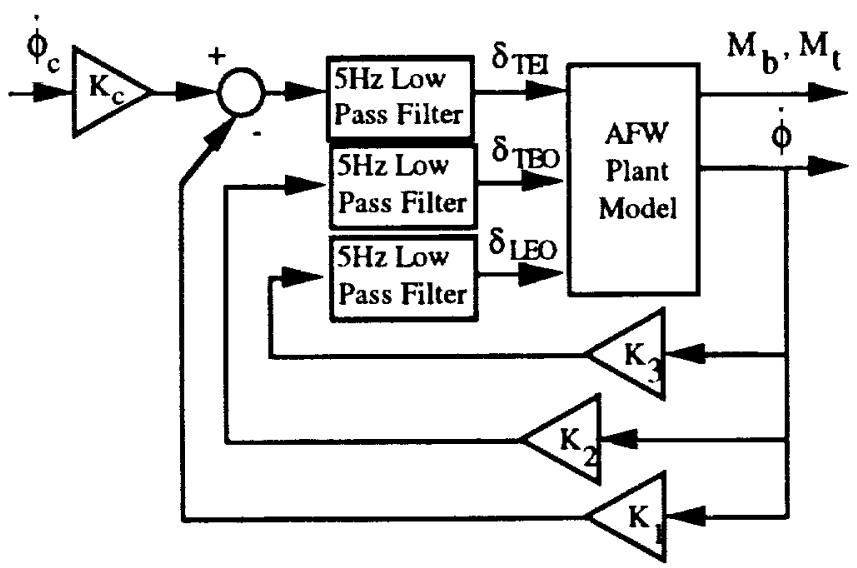

Fig. 3 RMLA Control Law Structure

outboard and trailing edge outboard control surface pairs. Left and right wing control surfaces in each pair are deflected differentially. The trailing edge inboard control surface pair is, in addition, commanded by an external ramp-hold command input. Outboard control surfaces are not commanded. To 
minimize the flexible effects which would be present while testing the RMLA control laws and to smooth the input command, a five Hertz lowpass filter was included in each loop of the system. As shown in the figure, the command input gain is $K_{c}$ and the feedback gains are $K_{1}, K_{2}$ and $K_{3}$

\section{"Load Effectiveness" of Control Surfaces}

The systematic approach used to define operation of the outboard control surfaces during roll maneuvers was straightforward. Essentially, it was a qualitative method which involved evaluating the "load effectiveness" of each outboard control surface or, in other words, it evaluated the ability of each outboard control surface to affect incremental loads generated during a roll maneuver. This analysis provided sufficient information to determine in which direction the leading edge outboard and trailing edge outboard control surface pairs should be deflected during roll maneuvers to produce decreases in the incremental loads. For this evaluation, the experimentally determined plant equations were used.

Simulations for the control surface load effectiveness study were performed with a modified control law structure which allowed all surfaces to be commanded by an external ramp-hold input and which included no roll rate feedback. As in the RMLA control law structure, right and left control surfaces are deflected differentially. This modified control structure is illustrated in Figure 4.

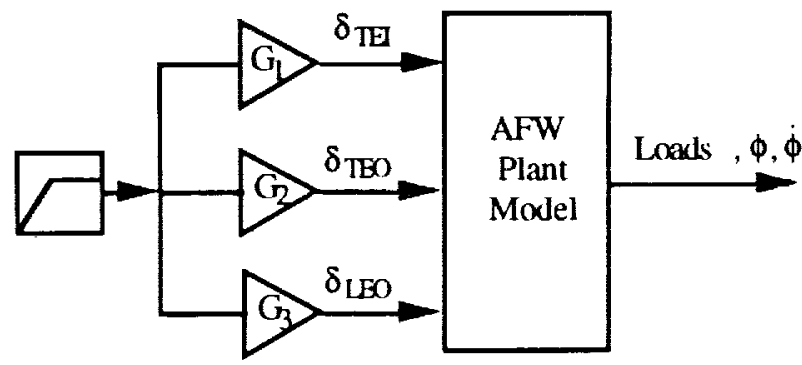

Fig. 4 Analysis Structure for "Load Effectiveness" Study

The procedure was simply to apply specified outboard control surface deflections in the positive and negative direction during simulated roll maneuvers while using the trailing edge inboard control surfaces to maintain a constant performance. Five sets of load time histori:s were obtained. The first set corresponded to a roll maneuver performed using the trailing edge inboard control surfaces only. The maneuver was performed to determine baseline incremental loads. The second set of incremental load time histories corresponded to a maneuver performed with a $+2^{\circ}$ deflection of the leading edge outboard control surface pair while the trailing edge inboard control surface pair was deflected a sufficient amount to maintain a roll performance of $90^{\circ}$ in 0.75 seconds. The third set of incremental load time histories was obtained in a similar manner except that the leading edge outboard control surface was deflected $-2^{\circ}$ during the maneuver. The fourth and fifth sets of incremental load time histories were obtained by performing the same roll maneuvers with the leading edge outboard control surface deflections held at zero and with the trailing edge outboard control surface deflections specified to be $+2^{\circ}$ and $-2^{\circ}$ during two separate roll maneuvers.
By plotting the five sets of incremental loads, it could be seen how outboard control surface deflections affected the incremental loads. Figure 5 illustrates some of the simulation results obtained. The +TEO label implies that the time history was obtained during a roll maneuver in which the trailing edge outboard control surface pair was deflected $+2^{\circ}$. A -TEO label implies a $-2^{0}$ deflection. The convention is similar for LEO. $B A S E$ labels the incremental load obtained in the baseline maneuver. The dashed line indicates the time at which the simulated roll maneuvers were terminated. As illustrated, negative deflections of the outboard control surface pairs were found to cause decreases in wing incremental bending loads. Similar results were obtained for the incremental torsion loads. Thus, it was decided to develop RMLA control laws which actuated both the leading edge outboard and trailing edge outboard control surface pairs in the negative direction during roll maneuvers.

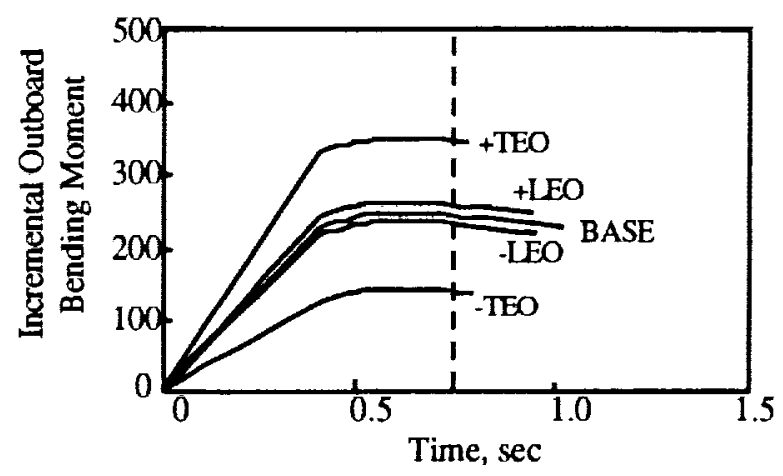

Fig. 5 Incremental Outboard Bending Moment Generated During Roll Maneuvers

\section{Selecting System Gains}

Using the information determined above and the RMLA control law structure defined in Figure 3, gains were chosen. The most important aspect of the design was that the control laws produced outboard control surface deflections during the maneuver in the desired direction to counteract incremental loads. In addition, it was necessary that the control laws produced reasonable control surface deflections which did not saturate at dynamic pressures of 150 or $250 \mathrm{psf}$. To achieve the target performance, the input gain, $K_{c}$, and feedback gains, $\mathrm{K}_{1}, \mathrm{~K}_{2}$, and $\mathrm{K}_{3}$, were iterated upon until the model rolled $90^{\circ}$ in 0.75 seconds.

Three control laws were developed. Control Law A was defined by roll rate feedback to the trailing edge inboard control surface pair and to the trailing edge outboard control surface pair. Control Law B was defined by roll rate feedback to the trailing edge inboard control surface pair and to the leading edge outboard control surface pair. Finally, the Baseline control law was defined by roll rate feedback to the trailing edge inboard control surface pair only. A summary of control system gains is listed in Table I.

\section{Stability Analysis}

A stability measure for each control law was predicted using a method 10 that defines stability margins in terms of simultaneous gain and phase changes in the loops of a multiloop system. Using the universal gain and phase margin 
Table I. Control Law Gains

\begin{tabular}{|cccl|}
\hline Gains & Control A & Control B & Baseline \\
\hline $\mathrm{K}_{\mathrm{C}}$ & 0.3500 & 0.3000 & 0.3500 \\
$\mathrm{~K}_{\mathrm{l}}$ & -0.0625 & -0.0667 & -0.0500 \\
$\mathrm{~K}_{2}$ & -0.0384 & 0 & 0 \\
$\mathrm{~K}_{3}$ & 0 & 0.0356 & 0 \\
\hline
\end{tabular}

diagram shown in Reference 10 and the minimum singular value of a linear system return difference matrix, regions of guaranteed stability over a system's operating frequency range could be predicted. For this application of the referenced technique system stability was presumed. It was established by performing eigenvalue analysis on the linear state space equivalent of each control system. The system return difference matrix is $[\mathrm{I}+\mathrm{GH}(\mathrm{i} \omega)]$, where $\mathrm{G}$ is the controller transfer matrix and $H$ is the plant transfer matrix. If the minimum singular value is near zero at any frequency, then the system is not robust to modeling errors. In the present study, the closed loop system with the Baseline Control Law implemented was determined analytically to have a minimum singular value of 0.49 while the closed loop system with Control Law A and Control Law B implemented were determined to have singular values of 0.79 and 0.77 , respectively. Minimum singular values in this range have a guaranteed minimum gain margin of $+10 \mathrm{~dB}$ and over $20^{\circ}$ phase margin in all loops. Analysis was performed for a dynamic pressure of $150 \mathrm{psf}$.

\section{Effect of Mass Eccentricity}

Due to the fact that the AFW wind-tunnel model mass center lies below the roll axis, an analytical study was conducted to quantify the "pendulum effect" relative to control surface moments acting on the model during a roll maneuver. This pendulum effect does not exist in free-flying vehicles and provided a significant restoring moment during roll.

In order to study the pendulum effect, the nonlinear roll equation (1) was expanded to include the effects of feedback,

$$
\begin{gathered}
I_{x x} \ddot{\phi}=L_{p} \dot{\phi}-m g l \sin \phi+\sum_{i=1}^{6} L_{\delta_{i}}\left(\delta_{i}+K_{j} \dot{\phi}\right) \\
\text { wF.sre } j=\left\{\begin{array}{l}
1 \\
2 \\
3
\end{array} \text { when } i=\left\{\begin{array}{l}
1 \text { or } 4 \\
2 \text { or } 5 \\
3 \text { or } 6
\end{array}\right.\right.
\end{gathered}
$$

where $j$ indicates the feedback gain associated with control surface $i$. Each of the four terms in the equation was integrated independently with time during several maneuvers of the AFW model with RMLA Control Law B implemented. An example of how the integration was performed is shown in the following equation.

$$
M_{p m}=\frac{1}{t_{f f}} \int_{t=0}^{t=t_{f}}|m g l \sin \phi(t)| d t
$$

As seen, the integral values were dimensionalized to moment units through division by $t_{f f}$ which is the "constant" time required for the AFW model to "free-fall" from $90^{\circ}$ to $0^{\circ}$ roll angle at $\mathrm{q}=150 \mathrm{psf}$.
In Figure 6, integrals of the pendulum rolling moment, $\mathrm{Mpm}_{\mathrm{pm}}$, and the rolling moment due to control surface deflection, $\mathrm{M}_{\mathrm{C}}$, are shown as functions of the time required to roll from $90^{\circ}$ to $0^{\circ}$. It is seen that the pendulum rolling moment is large relative to the rolling moment due to control surface deflection during slow roll maneuvers and provides a significant restoring force which aids the roll maneuver. Rolling faster "reduces" pendulum rolling moment contribution to total rolling moment.

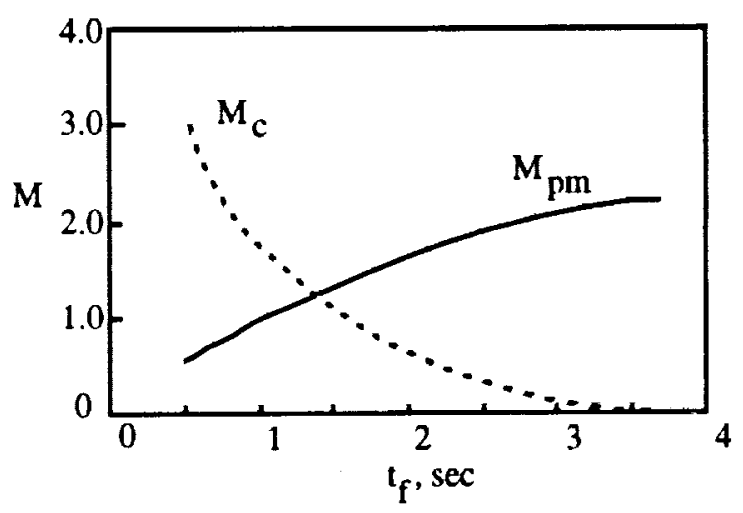

Fig. 6 Pendulum Rolling Moment and Control Surface Rolling Moment Integral Values

Because this pendulum effect is not representative of freeflying airplanes and because it was desired to demonstrate a control law concept for free-flying airplanes, the wind-tunnel model was rolled during testing at moderate to fast speeds in order to minimize the pendulum contribution.

\section{Test Procedure}

Control Law A and Control Law B were tested at dynamic pressures of q=150 psf, $200 \mathrm{psf}$, and $250 \mathrm{psf}$. Each RMLA controlled roll maneuver commenced with the model positioned at $90^{\circ}$ roll angle and was terminated shortly after the model rolled through $0^{\circ}$ roll angle. Baseline maneuvers were also performed at the same dynamic pressures and through the same roll angles. Maneuvers at $q=250 \mathrm{psf}$ were performed with the tip ballast decoupled in order to raise the open-loop flutter dynamic pressure above the testing dynamic pressure.

Roll maneuvers were also performed at $q=250$ psf and 260 psf with RMLA Control Law B implemented simultaneously with a flutter suppression control law. For these maneuvers, maneuvers commenced with the model positioned at $70^{\circ}$ roll angle and were terminated after the model rolled through $-20^{\circ}$. The tip ballast was coupled so that testing could be performed above the open-loop flutter dynamic pressure.

For both the RMLA control law testing and the multiple function testing, roll maneuvers were repeated several times at each dynamic pressure with the command input multiplied by a scale factor to make sure that data was obtained in the performance range of interest. Scale factors ranged from 0.8 to 1.5 . 


\section{Results and Discussion}

In this section, typical incremental load time histories obtained during RMLA controlled roll maneuvers are compared to baseline loads. Load alleviation results achieved using RMLA Control Law A and Control Law B are presented and the performance of the two control laws compared. Finally, an evaluation of the multiple function performance of RMLA Control Law B implemented with a flutter suppression control law is presented. Before describing these results, however, a brief discussion of test data reduction is necessary.

\section{Data Reduction}

Evaluation of the RMLA performance required some data reduction. First, peak incremental loads had to be extracted from test data for each roll maneuver performed. The incremental load was considered to be one-half the right wing bending or torsion moment minus one-half the corresponding left wing bending or torsion moment with the steady state load value removed. "Peak" incremental loads were computed as the maximum absolute value of each incremental load which occurred during the roll maneuvers. Four incremental loads were examined: outboard torsion moment, inboard torsion moment, outboard bending moment, and inboard bending moment. Second, because controlled roll maneuvers occurred during testing with different performance times, $t_{f}$, and because it was necessary to compare the RMLA maneuvers with baseline maneuvers having the same performance times, peak loads obtained in baseline maneuvers were interpolated. The interpolation of baseline loads was as a function of performance time. Thus, baseline loads were available for comparison to RMLA loads at performance times which were identical to those times achieved during RMLA controlled maneuvers.

\section{Typical Results}

Some typical results obtained during wind-tunnel evaluation of the RMLA control laws are shown in Figures 7(a) to (c). In these figures, the incremental loads obtained during a maneuver controlled by Control Law B and a baseline controlled maneuver are compared. The vertical dashed line indicates at what point in time the roll maneuver was terminated. A roll angle time history is shown in Figure 7(a). From this figure, it is apparent that both the RMLA controlled and baseline controlled roll maneuvers occurred with the same performance time, if. Thus, a fair comparison can be made between RMLA and baseline loads. Decreases in incremental torsion moments are observed in Figure 7(b). A 43\% reduction in the peak incremental value is observed. This substantial reduction in incremental torsion moment is typical of all the RMLA and baseline comparisons made. A similar comparison for the incremental bending moments, which is shown in Figure 7(c), indicates a slight increase in the peak load value. Specifically, a $10 \%$ increase in the peak incremental bending moment occurs.

\section{Load Alleviation Results}

Figures 8 and 9 contain bar graphs showing changes in the peak incremental loads during two RMLA controlled maneuvers and the percent change in these peak Ioads relative to peak incremental loads obtained in baseline controlled maneuvers with the same performance times.

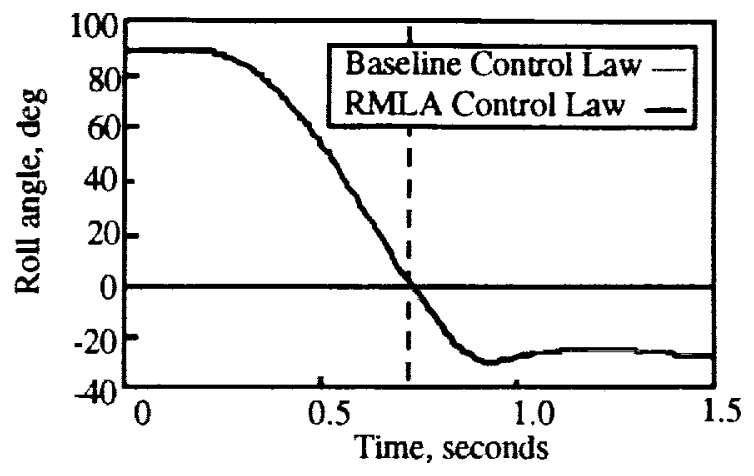

(a) Roll Angle

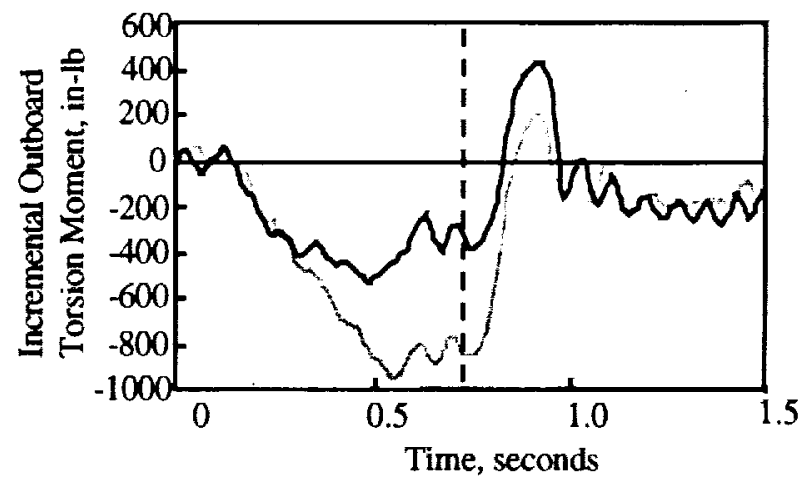

(b) Incremental Outboard Torsion Moment

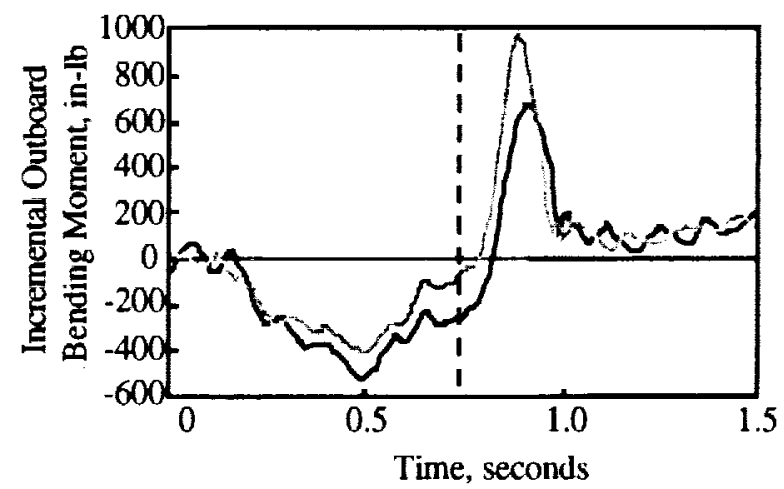

(c) Incremental Outboard Bending Moment

\section{Fig. 7 RMLA Controlled Maneuver Loads Compared to Baseline Loads at $\mathrm{q}=200 \mathrm{psf}$}

Figure 8 illustrates results using the RMLA Control Law A. In this particular event, the model rolled $90^{\circ}$ in 0.72 seconds at a dynamic pressure of $200 \mathrm{psf}$. The peak outboard incremental torsion moment is reduced relative to the baseline case by $38.9 \%$ and peak inboard incremental torsion moment is reduced by $53.8 \%$. Peak outboard incremental bending moment was shown to double and there was no change in the magnitude of the peak value of inboard incremental bending moment, although, there was a change in sign.

Figure 9 illustrates similar results from the testing of RMLA Control Law B. In this event, the model rolled through $90^{\circ}$ in 0.66 seconds at a dynamic pressure of $200 \mathrm{psf}$. As before, reductions in incremental torsion moments were achieved. Peak outboard incremental torsion moment decreased by $43.2 \%$ and peak inboard incremental torsion moment was 


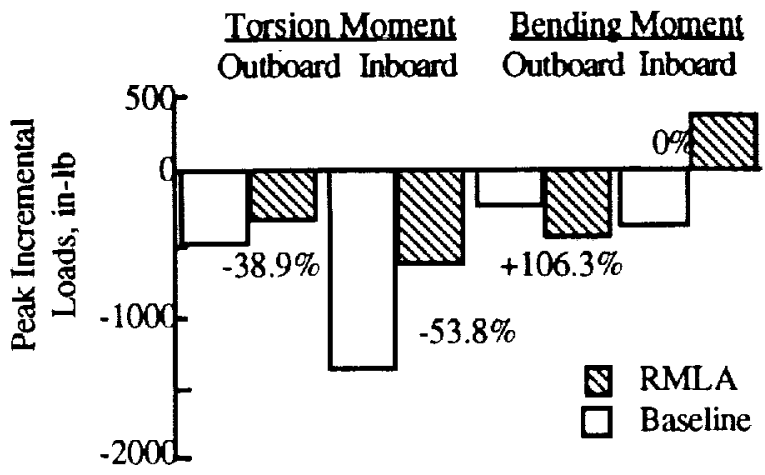

Fig. 8 Control Law A: Change in Peak Incremental Loads at $q=200$ psf and $_{\mathrm{f}}=0.72$ seconds

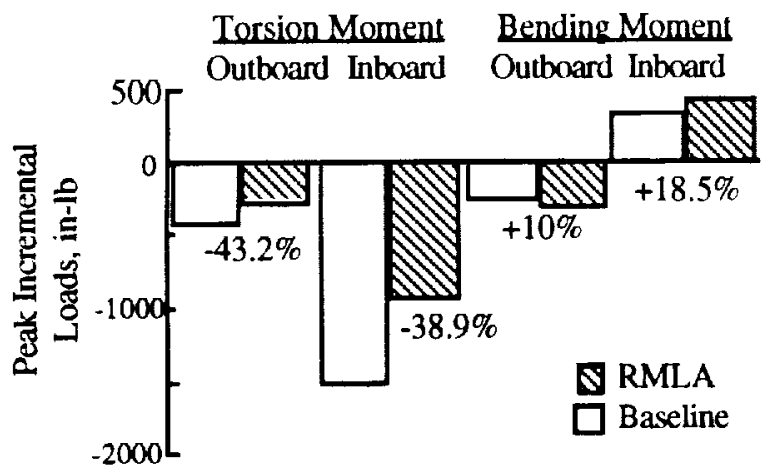

Fig. 9 Control Law B: Change in Peak Incremental Loads at $q=200 \mathrm{psf}$ and $\mathrm{t}_{\mathrm{f}}=0.66 \mathrm{~seconds}$

reduced by $38.9 \%$. Increases are seen in both outboard incremental bending moment and inboard incremental bending moment peak values, $10 \%$ and $18.5 \%$, respectively.

In order to gage how significant these results were for each load, a comparison can made between changes in peak incremental loads and the static load limits which are listed in Table II. For instance, it can be determined from Figure 9 that the percentage increase in peak inboard incremental bending moment represents about $75 \mathrm{in}-\mathrm{lb}$. Based on information from Table II, it is seen that this 75 in-lb change represents a very small percentage of the inboard bending moment load limit. On the contrary, with information from Figure 9, it is seen that the percentage decreases in peak inboard and outboard incremental torsion moments represent larger percentages of their respective torsion moment load limits. In this study, changes in the outboard torsion moment were considered the most significant as the amount of load alleviation due to implementation of RMLA control laws represented a substantial portion of each wing's capacity to support outboard torsion moments.

Table II Static Load Limits, in-lb

\begin{tabular}{|c|cccc|}
\multicolumn{1}{c}{} & \multicolumn{2}{c}{ Torsion } & \multicolumn{2}{c|}{$\begin{array}{c}\text { Bending } \\
\text { Moment }\end{array}$} \\
\hline & Right & Left & Right & Left \\
\hline Inboard & 9434 & 8929 & 18084 & 20965 \\
\hline Outboard & 1425 & 1627 & 3546 & 4099 \\
\hline
\end{tabular}

Figures 10 and 11 summarize the incremental load changes of the two RMLA control laws relative to the baseline loads at three dynamic pressures: $q=150,200$ and 250 psf. The percent changes indicated by solid symbols are plotted verse the time required for the model to complete the roll maneuver, $t_{f}$. Increasing time implies slower rolls. Several observations can be made.

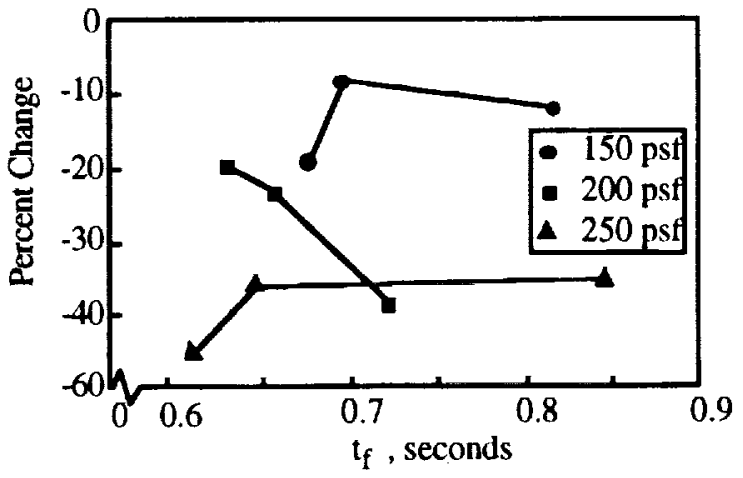

(a) Outboard Torsion Moment

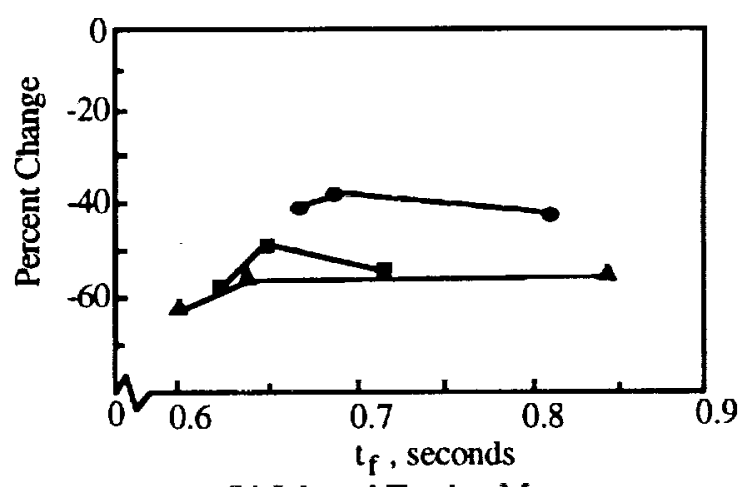

(b) Inboard Torsion Moment

Fig. 10 Control Law A: Load Alleviation Results

For Control Law A and Control Law B, both the inboard and outboard peak incremental torsion moments show decreases at all dynamic pressures and performance times, $t \mathrm{f}$, relative to the peak baseline incremental loads. In general, as seen in Figures 10 and 11 , reductions ranged from about $10 \%$ to $60 \%$ and the reductions tend to increase with increased dynamic pressure. At dynamic pressures of $q=150 \mathrm{psf}$ and $200 \mathrm{psf}$, rolling the model slower caused increases in the amount of reduction obtained in the peak incremental torsion moments. At $\mathrm{q}=250 \mathrm{psf}$, the trend is a slight increase as the model rolls at faster performance times.

By comparison, Control Law B caused a higher reduction in outboard incremental torsion moments than Control Law A, whereas, the reverse is true for the inboard incremental torsion moments. This suggests that, for the AFW wind-tunnel model, use of the leading edge outboard control surface pair is more effective at reducing the outboard incremental torsion moments than use of the trailing edge outboard control surface pair. Likewise, use of the trailing edge outboard control surface pair is more effective at decreasing inboard incremental torsion moments.

Control Law A and Control Law B differed more significantly in how peak incremental bending moments were affected during roll maneuvers. Although not shown, the peak values of both incremental bending moments showed 10-15\% increases relative to static load limits for maneuvers controlled 
by Control Law $\mathrm{A}$ and only $1 \%$ increases or slight decreases for maneuvers controlled by Control Law B.

In general, Control Law B demonstrated the better RMLA characteristics. Substantial reductions were achieved in both inboard and outboard incremental torsion moments without

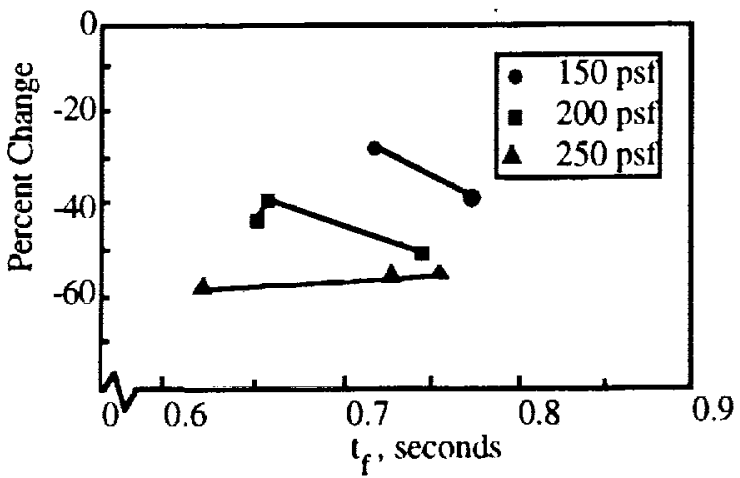

(a) Outboard Torsion Moment

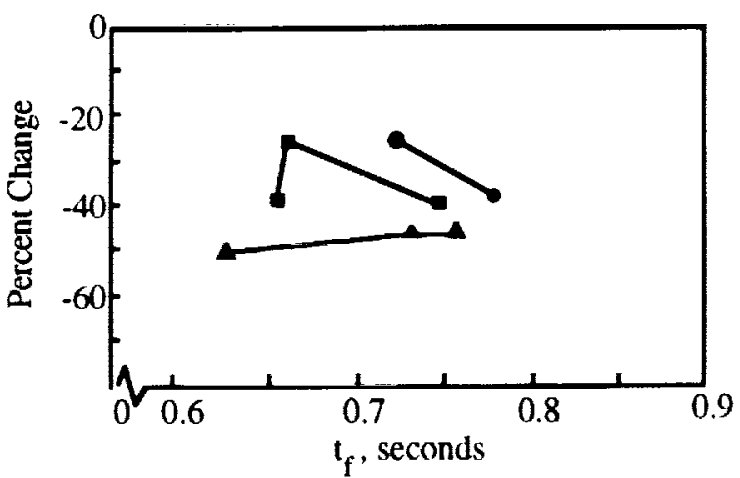

(b) Inboard Torsion Moment

Fig. 11 Control Law B: Load Alleviation Results

significant increases in incremental bending moments. Most importantly, a higher reduction was achieved in outboard torsion moment using Control Law B than was achieved with the use of Control Law A.

\section{Evaluation of Multiole Function Performance}

Successful roll maneuvers above the open-loop flutter dynamic pressure were achieved in testing with the RMLA Control Law B and a flutter suppression control law 11 implemented simultaneously on the digital controller ${ }^{12}$. Flutter did not occur during the maneuvers which implies that the flutter suppression control law was suppressing the instability during roll. It was, however, not possible to quantify incremental load reduction. Baseline data at the same Jynamic pressures with the AFW model in the tip ballast coupled configuration were not obtained and, thus, a qualitative evaluation of load reduction could not be made. Based on success at subcritical dynamic pressures, though, it is very likely that incremental load reduction occurred.

By observing control surface deflection time histories during a roll maneuver, it was seen that the RMLA and flutter suppression control laws operated simultaneously without significant interference. Figure 12 shows control surface deflections during a roll which occurred in 0.63 seconds at $\mathrm{q}=250 \mathrm{psf}$. The time histories are for right wing control surfaces only. The dashed lines indicate, again, the point in time at which the roll was terminated. The leading edge outboard and the trailing edge inboard control surface deflections due to RMLA are shown in Figures 12(a) and (b). Trailing edge outboard control surface deflection is due to the flutter suppression control law and is shown in Figure 12(c). The figure shows that the trailing edge outboard control surface oscillated at about $9.5 \mathrm{~Hz}$, the frequency required for flutter suppression, during and after the roll maneuver.

Thus, it has been demonstrated that the RMLA and flutter suppression control laws can be implemented simultaneously on the AFW digital controller and operate effectively together during roll maneuvers at dynamic pressures $11 \%$ above the critical flutter dynamic pressure.

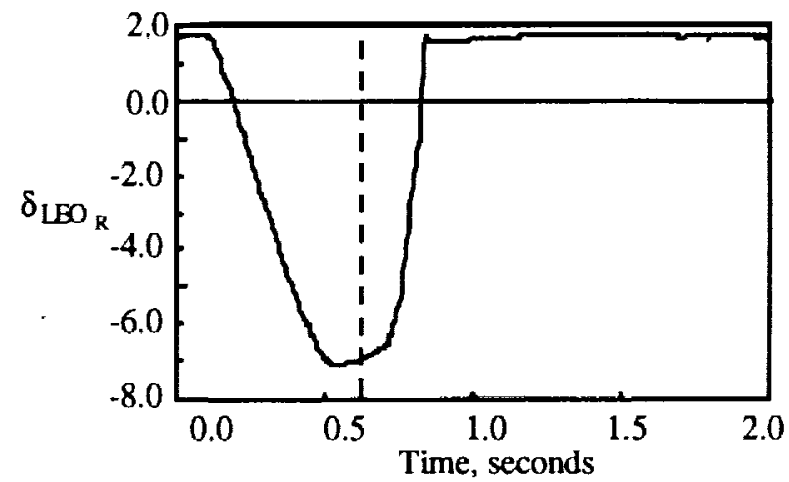

(a) LEO Control Surface Deflection Commanded by RMLA Control Law B

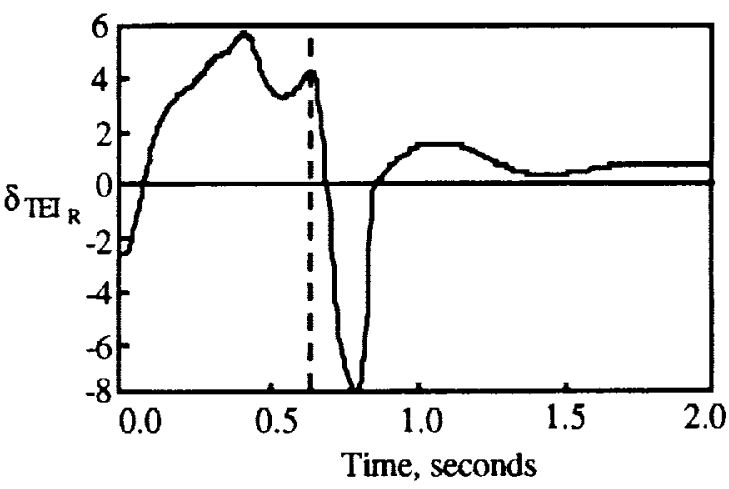

(b) TEI Control Surface Deflection Commanded by RMLA Control Law B

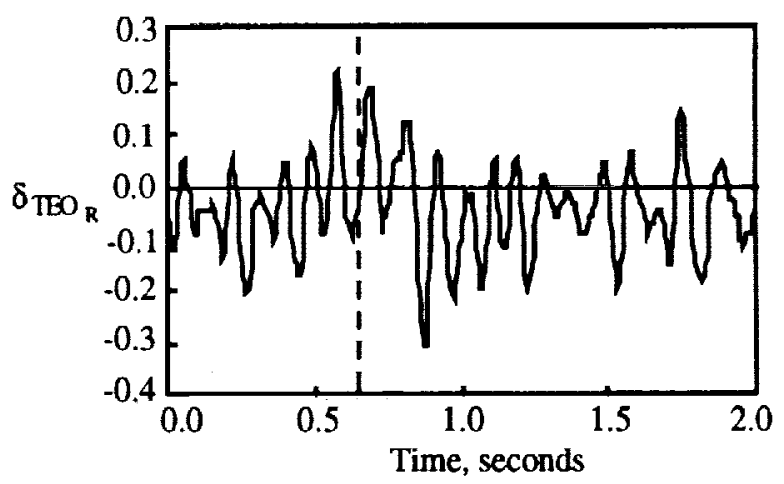

(c) TEO Control Surface Deflection Commanded by Flutter Suppression Control Law

Fig. 12 Control Surface Activity During Roll Maneuver With Simultaneous Implementation of RMLA and Flutter Suppression Control Laws 


\section{Conclusions}

In this study, a systematic approach to developing RMLA control laws was presented. Using this approach, two control laws were designed and experimentally evaluated, Control Law $A$ and Control Law B. The two control laws differed in that Control Law A used the trailing edge outboard control surface pair to perform load alleviation during roll maneuvers and Control Law B used the leading edge outboard control surface pair for the purpose of load alleviation during roll maneuvers. These control laws were experimentally evaluated on the AFW wind-tunnel model. In addition, Control Law B was implemented simultaneously with a flutter suppression control law in order to perform roll maneuvers at dynamic pressures above the open-loop flutter dynamic pressure.

The following is a list of the objectives which were met in this research:

1. Load alleviation during controlled roll maneuvers of a model in the wind tunnel was demonstrated. Active leading edge and trailing edge control surfaces were used to accomplish this objective.

2. In experimental evaluation of the two RMLA controllers, torsion moments showed up to a $60 \%$ reduction at some dynamic pressures and performance times relative to incremental torsion moments generated during baseline maneuvers. Results for changes in incremental bending moments during roll maneuvers varied.

3. Control Law B demonstrated better load reduction characteristics than Control Law A. A $10 \%$ to $20 \%$ larger reduction was observed in the outboard torsion moment during roll maneuvers controlled by Control Law B over those controlled by Control Law $A$.

4. It was demonstrated by experiment that the RMLA and flutter suppression control laws could be implemented simultaneously and operate effectively together during roll maneuvers at dynamic pressures at $11 \%$ above the critical flutter dynamic pressure.

\section{References}

${ }^{1}$ O'Connell, R.F., "Design, Development and Implementation of an Active Control System for Load Alleviation for a Commercial Transport Airplane," presented at the 49th Meeting of the AGARD Structures and Materials Panel, Cologne, Germany, October, 9, 1979.

${ }^{2}$ Rollwagen, G., Ellgoth, H., and Beuck, G., "Identification of Dynamic Response, Simulation and Design of a Highly Nonlinear Digital Load Alleviation System for a Modern Transport Aircraft," presented at the 17th Congress of the International Council of the Aeronautical Sciences, Stockholm, Sweden, September 9-14, 1990.

${ }^{3}$ Sandford, M.C., Abel, I., and Gray, D.L.,"Development and Demonstration of a Flutter-Suppression System Using Active Controls," NASA TR R-450, December 1975.

${ }^{4}$ Noll, T.E., and Huttsell, L.J.,"Wing Store Active Flutter Suppression - Correlation of Analyses and Wind-Tunnel Data," Journal of Aircraft, Vol. 16, July 1979, pp 491-497.

${ }^{5}$ Rogers, K.L., Hodges, G.E., and Felt, L., "Active Flutter Suppression - A Flight Demonstration," Journal of Aircraft, Vol. 12, June 1975, pp.551-556.
${ }^{6}$ Sensburg, O., Honlinger, H., Noll, T.E., and Huttsell, L.J, "Active Flutter Suppression of an F-4F Aircraft," Journal of Aircraft, Vol. 19, No. 5, May 1982, pp. 354-359.

${ }^{7}$ Miller, G.D., "Active Flexible Wing (AFW) Technology," AFWAL TR-87-3096, 1988.

${ }^{8}$ Perry, B.; Dunn, H. J.; and Sandford, M. C., "Control Law Parameterization for an Aeroelastic Wind-Tunnel Model Equipped with an Active Control System and Comparison with Experiment," Presented at the AIAA/ASME/ASCE/AHS Structures, Structural Dynamics and Materials Conference, Williamsburg, Virginia, April, 1989.

${ }^{9}$ Woods-Vedeler, J.A. and Pototzky, A.S., "Rolling Maneuver Load Alleviation Using Active Controls,"To be published as NASA TP, 1992.

10Mukhopadhyay, V. and Newsom, J. R., "Application of Matrix Singular Value Properties for Evaluating Gain and Phase Margins of Multiloop Systems," NASA TM 84524, 1982.

${ }^{11}$ Mukhopadhyay, Vivek, "Flutter Suppression Digital Control Law Design and Comparison with Experiment for the AFW Wind-Tunnel Model," Paper presented at the AIAA Dynamics Specialists Conference, Dallas, Texas, April 1617, 1992.

12 Hoadley, S.T. and McGraw, S.M.,"The Mult-Input/MultiOutput Multi-Function Digital Controller System for the AFW Wind-Tunnel Model," Paper presented at the AIAA Dynamics Specialists Conference, Dallas, Texas, April 1617,1992 

Davis Highway, Suite 1204 , Aflington. $7 A 22202-4302$, and to the Office of Mandgement and Budget. Paperwork Reduction Project (0704.0188), Washington, DC 20503.

\begin{tabular}{|l|l|l|}
\hline 1. AGENCY USE ONLY (Leave blank) & $\begin{array}{c}\text { 2. REPORT DATE } \\
\text { July } 1992\end{array}$ & $\begin{array}{c}\text { 3. REPORT TYPE AND DATES COVERED } \\
\text { Technical Memorandum }\end{array}$ \\
\hline
\end{tabular}

4. TITLE AND SUBTITLE

Rolling Maneuver Load Alleviation

Using Active Controls

WU 505-63-50-15

6. AUTHOR(S)

Jessica A. Woods-Vedeler and Anthony S. Pototzky

7. PERFORMING ORGANIZATION NAME(S) AND ADDRESS(ES)

NASA Langley Research Center

Hampton, VA 23665-5225

8. PERFORMING ORGANIZATION REPORT NUMBER

National Aeronautics and Space Administration

Washington, DC 20546-0001

NASA TM-107654

\section{SUPPLEMENTARY NOTES}

Presented at the AIAA Dynamic Specialists' Conference, Dallas, Texas, April 16-17, 1992.

Woods-Vedeler: NASA Langley Research Center, Hampton, VA; Pototzky: Lockheed

Engineering and Sciences Co., Hampton, VA.

12a. DISTRIBUTION/AVAILABILITY STATEMENT

Unclassified - Unlimited

Subject Category 05

13. ABSTRACT (Maximum 200 words)

Rolling Maneuver Load Alleviation (RMLA) has been demonstrated on the Active Flexible Wing (AFW) wind-tunnel model in the NASA Langley Transonic Dynamics Tunnel. The design objective was to develop a systematic approach for developing active control laws to alleviate wing incremental loads during roll maneuvers. Using linear load models for the AFW wind-tunnel model which were based on experimental measurements, two RMLA control laws were developed based on a singledegree-of-freedom roll model. The RMLA control laws utilized actuation of outboard control surface pairs to counteract incremental loads generated during rolling maneuvers and actuation of the trailing edge inboard control surface pairs to maintain roll performance. To evaluate the RMLA control laws, roll maneuvers were performed in the wind tunnel at dynamic pressures of 150,200 , and 250 psf and Mach numbers of $0.33, .38$, and .44 , respectively. Loads obtained during the maneuvers were compared to baseline maneuver loads. For both RMLA controllers, the incremental torsion moments were reduced by up to $60 \%$ at all dynamic pressures and performance times. Results for bending moment load reductions during roll maneuvers varied. In addition, in a multiple function test, RMLA and Flutter Suppression System (FSS) control laws were operated simultaneously during roll maneuvers at dynamic pressures $11 \%$ above the open-loop flutter dynamic pressure.

14. SUBIECT TERMS

Active controls; flutter suppression; leading edge control surface; load alleviation; roll maneuver
15. NUMBER OF PAGES 10

16. PAICE CODE $\mathrm{AO2}$

\begin{tabular}{|c|c|c|}
\hline $\begin{array}{l}\text { 17. SECURITY CLASSIFICATION } \\
\text { OF REPORT } \\
\text { Unclassified }\end{array}$ & $\begin{array}{l}\text { 18. SECURITY CLASSIFICATION } \\
\text { OF THIS PAGE } \\
\text { Unclassified }\end{array}$ & $\begin{array}{l}\text { 19. SECURITY CLASSIFICATION } \\
\text { OF ABSTRACT }\end{array}$ \\
\hline
\end{tabular}

